\title{
Metodologías para la enseñanza del léxico en el aprendizaje de lenguas extranjeras: un recorrido histórico
}

LUIS PABLO NÚÑEZ

Universidad de Granada

luispablo@ugr.es

Resumen: La importancia del léxico para el correcto aprendizaje de una lengua, la diversidad de aspectos que el profesor ha de tener en cuenta a la hora de su enseñanzaaprendizaje y la amplitud del léxico mismo, ha provocado una multitud de perspectivas en su didáctica. Este trabajo expone cuáles han sido las metodologías que han surgido a lo largo del siglo XX-XXI para la enseñanza-aprendizaje del léxico de una nueva lengua y el aprovechamiento que ha recibido de ellas la didáctica del español como lengua extranjera (ELE).

Palabras clave: léxico, vocabulario, aprendizaje, metodología, español lengua extranjera (ELE).

\section{Methodologies for the teaching of the lexicon in the learning of second languages: a historical journey}

Abstract: The lexicon is a very important element for the correct learning of a language. Because of the diversity of aspects that the teacher has to take into account when teaching it, and the breadth of the lexicon itself, a great number of didactic perspectives have arisen. This paper exposes the diverse methodological proposals that arose throughout the XXXXI centuries for the teaching of the lexicon, and the improvements that the didactics of Spanish as a Foreign Language (SFL) has obtained from them.

Keywords: lexicon, vocabulary, learning improvement, methodologies, Spanish as a foreign language (SFL).

\section{El léxico en la enseñanza-aprendizaje de una lengua y la búsqueda de estructuración de un sistema abierto}

El léxico de una lengua forma un conjunto abierto difícil de sistematizar. Los diccionarios generales, que tratan de recogerlo de acuerdo con varios criterios (diatópicos, diacrónicos, de uso, de frecuencia, etc.), muestran su amplitud y optan generalmente por el orden alfabético para facilitar su localización. La menor presencia de diccionarios onomasiológicos, donde las voces se ordenan conceptualmente, es una muestra de la dificultad que se da para mostrar las complejas relaciones entre los términos y los significados. Solo el léxico compuesto por series cerradas (como los días de la semana, los meses, las estaciones, los colores, etc.) o aquel con posible función gramatical (artículos, pronombres personales, preposiciones, conjunciones, adjetivos y adverbios cuantificadores del tipo mucho, poco, etc.), estructurable en conjuntos cerrados, no presenta grandes dificultades de sistematización, pues es incluido en la gramática. 
En el léxico convergen muchos aspectos que hacen difícil su enseñanza-aprendizaje, bien sea por su forma, su significado o su uso: desde el punto de vista semántico, cuestiones de aparente sinonimia añaden matices distintivos de unas voces frente a otras, o añaden múltiples significados (polisemia) o dependencias (hiperonimia/hiponimia); el significado puede además cambiar, según se trate del denotado, del figurado o del surgido en una combinación con otras palabras: pensemos por ejemplo en los matices que distinguen oír/escuchar, mercado/feria - esto es, un 'mercado extraordinario que solo se celebra en una fecha y lugar concretos' - o en las locuciones donde el significado del conjunto no es exactamente el de la suma de las palabras que la forman, como en tomar el pelo, irse [algo o alguien] a la porra, irse a tomar viento, mandar [algo o a alguien] a tomar vientos, irse con viento fresco. Desde el punto de vista sintáctico, las restricciones combinatorias provocadas por el aspecto léxico o los regímenes preposicionales u otros usos fosilizados, como sucede en la fraseología, impiden la combinación libre. cf. romper un trato/*romper tres tratos; coger/tomar el autobús vs. tomar $\rightarrow$ un café/*coger $\rightarrow$ un café. Por otra parte, las variedades diafásicas y diastráticas - es decir, los diversos registros: culto, coloquial, familiar, vulgar, argot - afectan en mayor medida al léxico que a otros planos de la lengua $\mathrm{y}$, asimismo, la variación diacrónica provoca fluctuación de usos en ciertos contextos sociales (neologismos o palabras desusadas). Todos estos aspectos, junto con la variación diatópica del español en las distintas regiones españolas e hispanoamericanas o el carácter cultural del léxico, debe tenerlos en cuenta el profesor o profesora de ELE a la hora de enseñar español.

La Lingüística cognitiva ha abordado el aprendizaje del léxico y de las segundas lenguas en general (Segoviano, 1996; Suau Jiménez ${ }^{1}, 2000$ ) y ha llegado a la conclusión de que el aprendizaje de las palabras se establece fundamentalmente mediante asociaciones semánticas (agrupaciones léxicas), es decir, con el significado como elemento estructurador, y también, aunque en menor medida, mediante asociaciones formales (contraposición formal, ya por oposición fonético-fonológica, como en casa/caza, o por ampliación y contraste morfológico: mesa-mesilla).

Otro aspecto que influye, según la lingüística cognitiva, en la adquisición de léxico es la competencia que tiene el hablante en su lengua materna, ya que esto condiciona el aprendizaje que pueda llevar a cabo en la otra lengua. Del mismo modo ocurriría con la competencia gramatical.

Las interferencias con los sistemas léxicos y/o morfológicos de la lengua materna del alumno pueden también condicionar los errores de aprendizaje en el léxico, al generalizar normas regulares con irregulares (por ejemplo: yo *cabo, *madridiano) o al asociar falsos amigos o regímenes verbales de una lengua con otra ${ }^{2}$. La Lingüística aplicada ha tratado también de valorar mediante el análisis de errores y los estudios contrastivos estas interferencias.

Todos estos aspectos suponen que la enseñanza-aprendizaje del léxico implique una serie de consideraciones previas:

\footnotetext{
${ }^{1}$ La obra de Suau Jiménez está formado por dos partes: una primera, teórica, sobre el aprendizaje del léxico en una lengua extranjera, y una segunda parte, práctica, sobre un experimento con un grupo de alumnos para saber cómo el contexto textual influye a la hora de determinar el aprendizaje del léxico. El texto fue en origen una tesis doctoral (La inferencia léxica en el aprendizaje de lenguas extranjeras, 1997).

${ }^{2}$ Véase a este respecto el artículo de Nunes/Vaz da Silva/Duarte (2001), sobre los problemas de los hispanohablantes a la hora de aprender los usos de la preposición "a" en portugués, especialmente en los casos de perífrasis verbales y regímenes verbales.
} 
- la primera es que, al ser un sistema abierto, el aprendizaje de palabras no finaliza nunca, ni aun cuando somos adultos, en el caso de los nativos, ni —en el caso de los extranjeros - al finalizar el curso concreto que el profesor debe impartir a los alumnos de un cierto nivel. Debido a su número, el aprendizaje del léxico exige obligatoriamente centrarse en una gradación o en una reducción, normalmente basada en frecuencias o en el uso específico del ámbito en el que va a usar la lengua el aprendiz; esto ha conllevado en muchos casos su dependencia de los ámbitos temáticos presentes en los manuales de enseñanza de lenguas. En la enseñanza de español con fines específicos es incluso más notorio;

- la segunda es que el aprendizaje del léxico en sí mismo, como voces individuales, no es suficiente: es necesario conocer su funcionamiento sintáctico, es decir, con qué palabras puede combinarse y con cuáles no, y las posibilidades semánticas de sustitución por voces semejantes sin producir agramaticalidad o extrañeza, ya sea por incumplir reglas lingüísticas o por inaceptabilidad semántica. Esto es lo que ha motivado que se hable de los ejes sintagmático y paradigmático al tratar el vocabulario y que, frente al difuso concepto de "palabra", se haya optado, como se hace en la lexicología, por el de lexía o unidad léxica, donde se incluirían tanto las voces individuales (silla, plato, lavar) como las resultantes de la composición (lavavajillas) o las pluriverbales (máquina de afeitar), pues lo relevante es no tanto la forma, sino el concepto que designa;

- la tercera es que, sobre los caracteres lingüísticos propios de cada voz impuestos por el sistema lingüístico en los planos semánticos y sintácticos, se superponen las restricciones o limitaciones de uso de acuerdo con el registro, situación geográfica, situación temporal y social del hablante y de su interlocutor, es decir, el contexto elocutivo. Este es el que puede producir variaciones de determinadas voces, como acortamientos, usos impropios, etc., pero, en todo caso, favorecedores de la comunicación de acuerdo con esa situación comunicativa concreta.

Los puntos señalados son necesarios para aprender y usar correctamente una palabra. Siendo conscientes de ello, los docentes podrán solucionar los errores frecuentes o emplear estrategias lingüísticas adecuadas ante la incapacidad para encontrar la palabra exacta, el uso inapropiado de una palabra, la reformulación mediante nuevas estructuras léxicas o el empleo de perífrasis sustitutivas, ya sea sirviéndose de técnicas visuales (usando gestos, imágenes) o técnicas verbales (escalas jerárquicas, hiperonimia, mapas de asociación, definiciones, equivalencias, etc.): para estos aspectos de didáctica del vocabulario, puede consultarse por ejemplo Meara (2009) y los capítulos sobre la competencia léxicosemántica y la enseñanza/aprendizaje del vocabulario del Vademécum (Sánchez Lobato/Santos Gargallo, 2004) y del manual de Arco Libros de Santiago Guervós/Fernández González (2017).

En este texto veremos algunas de las propuestas metodológicas que, siguiendo la evolución histórica de las teorías lingüísticas, los lingüistas y pedagogos han ideado para enseñar vocabulario desde la segunda mitad del siglo XX. No es el propósito de este artículo, por su limitación de espacio y de tiempo, dar cuenta de todas, pero sí señalar las grandes líneas; puede afirmarse en todo caso que muchas de estas teorizaciones y sus aplicaciones metodológicas derivadas buscan estructurar este sistema abierto y someter así a reglas su aprendizaje, bien mediante la estructuración del significado en semas, la distribución del 
vocabulario según su frecuencia, bien haciendo hincapié en el significado y su inferencia o en las asociaciones y relaciones entre términos (contextos y combinaciones sintácticas).

Por último, hay que distinguir dos perspectivas posibles a la hora de abordar el estudio de la enseñanza/aprendizaje del léxico: por una parte, la perspectiva de la lengua materna y, por otra, la de la enseñanza/aprendizaje de una nueva lengua, aunque ambas convergen en muchos aspectos. Para la primera, estudios de hace varias décadas enfocados a hablantes nativos, no extranjeros, como los de Jiménez Jiménez (1986) o Pastora Herrero (1990), parten de la teoría lexicológica. En otras lenguas encontramos investigaciones semejantes anteriores, como las de Picoche (1977) para el francés, sobre la aplicación didáctica de principios teóricos semánticos y léxicos, o Wallace (1982) y Carter/McCarthy $(1988,2016)$ para el inglés.

En cuanto a la enseñanza del léxico en segundas lenguas, la lingüística anglosajona lleva clara ventaja, pues estudia desde antes las implicaciones didácticas del léxico: $c f$. Richards (1974), Kruse (1979), Garins/Redman (1986), Williams (1986), Nation (1990, 2013), Meara (1983, 1992, 2009), Coady/Huckin (1997), Bogaards/Laufer (2004) y Barfield/Fitzpatrick (2009), Williams (1986), Meara (1992), Hunston(1997) y Hunt (2005) sintetizan otros estudios y técnicas para la enseñanza/aprendizaje del léxico en inglés como lengua extranjera (EFL). En español existe también una amplia bibliografía, entre cuyas obras recientes podrían citarse, por orden cronológico, las de Santamaría Pérez (2006), Higueras García (2007), Soler Albiñana (2008), Kaufmann (2009) y Serra Alegre/Veyrat Rigat/Rodríguez Pellicer (2010). Esta es la perspectiva que a nosotros nos interesa más y a la que nos referiremos principalmente, usando en ocasiones ejemplos tomados de nuestro estudio inédito (Pablo, 2003) sobre la tipología de ejercicios léxicos de un corpus de cuatrocientos ejercicios de vocabulario tomados de veinte manuales de ELE.

\section{Elementos fundamentales en el tratamiento del vocabulario}

Antes de entrar en las diferentes teorías y metodologías, es preciso dedicar un apartado a las principales perspectivas con las que se ha abordado el análisis del léxico, esto es, a los aspectos principales que se suelen considerar en la enseñanza/aprendizaje de las unidades léxicas (lo que para Nation [1990: 29] respondería a la pregunta «What is involved in learning a word?).

\subsection{Forma y significado}

Es la división clásica en el tratamiento del vocabulario; de hecho, algunos autores, como Wallace (1982), se basan en ella para su tipología de ejercicios léxicos. El primer acercamiento a una unidad léxica se realiza siempre por la forma, bien sea mediante su reconocimiento escrito (ortografía) o mediante su forma hablada (pronunciación). Si bien pueden existir dificultades mayores en la escritura según las lenguas (por ejemplo, cuestiones de homófonos/homógrafos, la separación silábica, el empleo de apóstrofos o guiones en inglés, las tildes en español y francés), el vocabulario aquí no suele ser empleado más que como un medio para un fin fonético, consistente en la identificación y distinción de fonemas mediante ejercicios de ortología y articulación.

En el aspecto de contenido, es usual la división entre palabras llenas y palabras vacías de significado, o significado léxico y significado gramatical. Este último se basa en las estructuras y funciones y ha tenido especial relevancia en el Estructuralismo. El significado léxico tiene en cuenta dos factores: la denotación y la connotación, es decir, lo que significa esa palabra y lo que puede llegar a significar según el contexto o situación. 
Desgraciadamente, todavía no se han hecho demasiados estudios sobre el significado pragmático del léxico, y únicamente se dan ejemplos concretos sobre palabras polisémicas. No conocemos aún las reglas pragmáticas que hacen que una palabra, o un grupo, puedan cambiar su significado.

La traducción también se basa en la equivalencia de significados. Los falsos amigos, sin embargo, aprovechan la equivalencia de formas para provocar la equivalencia de significados, lo que provoca el error en el aprendizaje. Pero si esta equivalencia es posible se debe a las mismas estructuraciones de los campos semánticos entre esas lenguas: ¿sería posible traducir a otra lengua una palabra cuyo objeto designado no existe en ella? No de forma plena. Pues esto es lo que ocurre con las estructuraciones semánticas: cuando dos lenguas comparten una misma estructuración, la traducción es posible; cuando no comparten esa misma estructuración, la traducción no es posible o requiere matices (esto es, se traducen no con un equivalente, sino con una explicación o explicación). Pongamos por ejemplo el manido de los colores de la lengua de los esquimales: si en esa lengua el color blanco tiene más de diez matices, es decir, palabras distintas para cada uno de esos blancos mates, brillantes, etc., difícilmente podremos traducir todas esas palabras utilizando una sola en la lengua extranjera. Igual ocurre con este otro ejemplo clásico sobre la estructuración semántica de los colores en inglés y galés (Bauer, 1998: 32):

\begin{tabular}{|l|l|}
\hline Green & \begin{tabular}{|l|} 
Gwyrdd \\
\hline Blue
\end{tabular} \\
\hline Grey & Glass \\
\hline Brown & Ilwyd \\
\hline
\end{tabular}

Figura 1. Estructura semántica de colores en inglés y galés de Bauer (1998)

Los problemas de correspondencia en este caso son estrictamente semánticos. Nation (1990: 31) considera que la correspondencia semántica es relevante, pues facilitar el aprendizaje, especialmente desde un punto comparativo si el concepto de la L1 coincide con el de la L2. En este sentido, los avances en semántica estructural, mediante la determinación de semas, ha sido también aprovechada por la Lingüística Aplicada, para formular ejercicios léxicos de determinación de rasgos semánticos por parte del alumno, como el que encontramos en el antiguo Ven 2 (1991: 69):

\begin{tabular}{|l|l|l|l|l|l|}
\hline & acera & bordillo & calzada & $\begin{array}{l}\text { Un carril en } \\
\text { cada sentido }\end{array}$ & $\begin{array}{l}\text { Varios carriles } \\
\text { en cada sentido }\end{array}$ \\
\hline Calle & $\mathrm{X}$ & $\mathrm{X}$ & $\mathrm{X}$ & $\mathrm{X}$ & $(\mathrm{X})$ \\
\hline Avenida & $\mathrm{X}$ & $\mathrm{X}$ & $\mathrm{X}$ & & $\mathrm{X}$ \\
\hline Paseo & $\mathrm{X}$ & $\mathrm{X}$ & $\mathrm{X}$ & $(\mathrm{X})$ & $\mathrm{X}$ \\
\hline Plaza & $\mathrm{X}$ & $\mathrm{X}$ & $\mathrm{X}$ & & \\
\hline Glorieta & $\mathrm{X}$ & $\mathrm{X}$ & $\mathrm{X}$ & & \\
\hline Carretera & & & $\mathrm{X}$ & $\mathrm{X}$ & \\
\hline Autopista & & & $\mathrm{X}$ & & \\
\hline Camino & & & & & \\
\hline sendero & & & & & \\
\hline
\end{tabular}

Figura 2. Ejercicio de rasgos semánticos. Fuente: Ven 2, libro del profesor, p. 69 


\subsection{Estructuras y colocaciones}

Las estructuras y colocaciones, o combinaciones, dependen en buena parte de la semántica, aunque están más estrechamente ligadas a la sintaxis. Determinar las combinaciones usuales o los tipos de palabras con los que suele aparecer una unidad léxica puede ayudar a comprender mejor el concepto y ampliar el vocabulario: por ejemplo, el sustantivo sabor en español se combina con adjetivos como ácido/amargo, agradable/exquisito/intenso/repulsivo... o verbos como apreciar, notar, percibir, etc. Podemos encontrar ejemplos abundantes en las diferentes lenguas gracias a los recientes diccionarios combinatorios. Tomamos el siguiente ejemplo de Socios 1 (Corpas/Martínez 1999: 139):

¿Con qué verbos relacionarías estos sustantivos?

$\begin{array}{llll}\text { Una reunión } & \text { La documentación } & \text { El teléfono } & \text { Un contrato } \\ \text { Una entrevista } & \text { Un pedido } & \text { Un paquete } & \\ \text { Una visita } & \text { Una noticia } & \text { Una carta } & \end{array}$

Aplazar: una reunión, una entrevista...

Preparar

Mandar

Comunicar

Concertar

Atender

Contestar

Firmar

Figura 3. Ejemplo de combinaciones léxicas del manual Socios 1

Las combinaciones pueden estar determinadas por la semántica y el aspecto léxico, como hemos visto, pero también por la gramática. Es lo que ocurre, por ejemplo, con este otro ejemplo del manual Español en el hotel (Moreno/Tuts, 2001: 35)

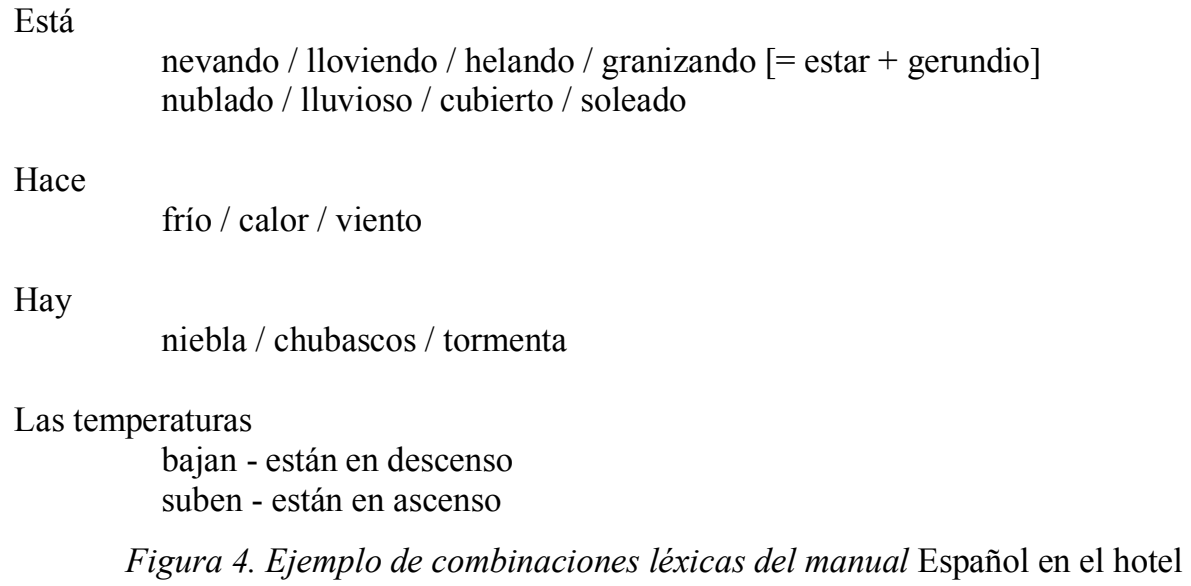

Hay que añadir a estas las locuciones y expresiones fraseológicas, de uso frecuente, más o menos fijas en distintos grados.

\subsection{Estadística léxica: frecuencias, vocabulario de uso y disponibilidad}

Uno de los problemas que tenían los profesores a la hora de enseñar el léxico es que no sabían, salvo guiados por criterios psicológicos, qué palabras eran las necesarias para ser enseñadas, las más frecuentes y habituales en el español. Esto se investigó en las lenguas inglesa $\mathrm{y}$ francesa $\mathrm{y}$, a principios del siglo $\mathrm{XX}$, en la española por hispanistas 
norteamericanos como Buchanan (A Graded Spanish Word Book. Toronto, Univ. of Toronto Press, 1927), H. Keniston (A Basic List of Spanish Words and Idioms, Chicago, 1933) o Thornkique (The Teachers Word Book of 30000 Words, New York, 1945).

Siguiendo esta línea, surgieron los estudios de Víctor García Hoz (Vocabulario usual, vocabulario común y vocabulario fundamental, 1953 — cf. García Hoz, 1953 y 1977—), que, basados en un corpus de 240000 palabras, consideraron el vocabulario usual (es decir, corriente o estándar) en torno a 12500 palabras, vocabulario común, unas 2000, y vocabulario fundamental, unas 200. Posteriormente, con los avances de la informática y los centros de cálculo, surgieron los diccionarios de frecuencias en regla: el francés, en 1971; el inglés, en 1944 y 1976; el español, en 1964 y 1995, por la Universidad de Oviedo, y estos resultados se matizaron más, pero las conclusiones de décadas anteriores siguen siendo válidas en sus principios.

Los resultados, aprovechados por manuales de enseñanza de segundas lenguas y diccionarios, arrojaron que con unas 5000 palabras se puede cubrir el $95 \%$ de la comprensión de un texto, y que, de esas, un mínimo conjunto puede tener un alto porcentaje en un texto. A medida que aumentamos las palabras (1000 palabras más), el porcentaje disminuye de forma muy acusada: si las cien primeras palabras son un $59 \%$, las siguientes mil en frecuencia solo darían un $27 \%$.

De hecho, las investigaciones de Nation (1990) afirman que, en un texto medio, las palabras de alta frecuencia alcanzan un $87 \%$ del texto; el léxico más complejo llegaría a ocupar un $8 \%$; las palabras técnicas, un $3 \% \mathrm{y}$, finalmente, las palabras de baja frecuencia, un $2 \%$ del texto (datos citados por Suau Jiménez, 2000: 49), de aquí que Nation proponga potenciar el aprendizaje del más frecuente y para ese léxico menos habitual deducir su significado a través del contexto.

De esta manera, la estadística léxica, retomada en las teorías de corpus, tiene una utilidad clara y un protagonismo fundamental en la enseñanza de segundas lenguas (la frecuencia de aparición de una palabra condiciona el aprendizaje de la misma), y de estas investigaciones se han hecho eco los libros denominados genéricamente "léxicos fundamentales", surgidos en lenguas como el inglés, francés y español, las lecturas graduadas y diccionarios como The New Method English Dictionary de Michael P. West y James Gareth (ediciones desde 1935), el Cambridge English Lexicon: A Graded Word List for Materials Writers and Course designers (1980) de Roland Hindmarsh, las listas de vocabulario graduadas como The Cambridge English: Preliminary and Preliminary for Schools Vocabulary List y, en español, el diccionario Cumbre y el DiPELE de Vox/Bibliograf (1995), específicamente dirigido a estudiantes de español como lengua extranjera. Se da el hecho, además, de que estudios como el de H. Eaton en 1940 (An English-French-German-Spanish Word Frequency Dictionary) mostraron que en las lenguas europeas hay un alto grado de similitud en las palabras más frecuentes (aunque buena parte de ellas sean gramaticales).

Otro de los aspectos estudiados en torno al uso del léxico, en cierto modo relacionado con la frecuencia, es el de la disponibilidad léxica de un hablante, es decir, el estudio de las voces que vendrían a la mente de un hablante ante un determinado estímulo o en una determinada situación. Así, se hace una distinción entre vocabulario pasivo (el que se comprende) y vocabulario activo (el que es capaz de utilizar y emplear). El primero, el pasivo, se relaciona básicamente con dos instrumentos: las lecturas, en donde el alumno puede llegar a adquirir una cierta cantidad de léxico, pero sin llegar a memorizarla; se interioriza en una fase de pre-aprendizaje, de reconocimiento únicamente. Sería el caso del diccionario bilingüe, que, al ser consultado, soluciona una duda, pero no hace aprender la 
palabra consultada necesariamente. El vocabulario activo conlleva un proceso de aprendizaje mayor y sobre todo el empleo de la palabra en sus contextos adecuados.

La disponibilidad léxica se ha medido también sobre personas que aprenden una nueva lengua y permite conocer el grado de asimilación de vocabulario; $c f$. los estudios de Samper (2002) y Jiménez Catalán (2014).

\section{El tratamiento del léxico según las distintas metodologías}

La enseñanza/aprendizaje del léxico —en su reconocimiento, asimilación, sistematización y uso - es uno de los aspectos esenciales incluido en todo método de enseñanza-aprendizaje de segundas lenguas, pero el tratamiento mayor o menor que se le da en los manuales depende de la época y de la metodología en la que se basen: el léxico no es sino uno de los varios planos considerados en esas metodologías, centradas en las estrategias para potenciar el aprendizaje de una lengua. Hoy, la competencia léxica debe abordar, como dice el Marco (MCER, 2002: 126) «el conocimiento del vocabulario de una lengua y la capacidad para utilizarlo».

De acuerdo con Richards/Rodgers (2009) y Roser Morante (2005: 12-36), pueden distinguirse varias etapas cronológicas principales en la evolución de los métodos de enseñanza de segundas lenguas: una primera abarcaría hasta los años 70, una segunda el periodo 1970-1983/1986 aproximadamente y una tercera desde 1983/86 hasta hoy (ahora bien, no hay que considerarlas fechas estrictas, pues las metodologías se basan en avances teóricos y estos se desarrollan o reestructuran durante varios años). Sánchez Pérez (2009) y García Giménez (2008) ofrecen también descripciones de esta evolución complementarias a la que exponemos, al considerar también el papel del profesor y del alumno. Pasamos a continuación a describir las principales propuestas metodológicas de esos periodos.

\subsection{El método tradicional}

El método tradicional es también conocido como el método de gramática y traducción, pues las prácticas de traducción de la L2 a la lengua materna y viceversa suponían el modelo de adquisición más habitual. Según este método, la lengua es un conjunto de reglas gramaticales y excepciones que hay que aprender, en muchas ocasiones de memoria o mediante la deducción. Los textos escritos son la base del aprendizaje, ocasionalmente recitados en voz alta para ejercitar la pronunciación.

El léxico en el método tradicional se supedita a estos dos objetivos principales (aprender gramática y traducir textos) y solo se explica si implica un aprendizaje de un aspecto gramatical o la mejora de una traducción, generalmente realizada palabra a palabra o por oraciones. Este método potencia la creación de listas de voces descontextualizadas o agrupadas por contenidos temáticos que se memorizan.

El método tradicional de gramática y traducción se ha empleado durante siglos, pero ha sido denigrado ante la llegada de nuevos enfoques pedagógicos; sin embargo, a pesar de sus carencias, no ha de descartarse su utilidad parcial, especialmente cuando el alumno presenta una lengua materna tipológicamente muy separada: la metodología tradicional, reforzada con el análisis de errores, sigue aún presente en las escuelas y universidades chinas al aprender segundas lenguas, incluido el español; además, la traducción refuerza estrategias para la correcta comprensión de la semántica y la sintaxis oracional.

Muchos manuales recientes retoman esta metodología, aun cuando hayan sido complementados con ejercicios comunicativos que favorecen la conversación, como ocurre con el de Ángeles Encinar (1991 y 2000) o con el de Sánchez Lobato y Aguirre (1992), donde los capítulos parten de listados estructurados por áreas temáticas. En otros casos, como Hernández (2002), los listados se vinculan con la traducción, con los procedimientos 
morfológicos ( $c f$. Moral y Olmo, 2001) o en el cederrón de Cumbre: practica tu vocabulario (2003), con los estudios de frecuencias (corpus). Otras propuestas didácticas del léxico recurren a la ilustración ( $c f$. Pacios Jiménez, 1999). Prosigue, pues, su empleo como refuerzo de otros métodos.

\subsection{El método natural y método directo}

El método directo surgió en Francia y Alemania a finales del siglo XIX como una reacción ante el método de gramática-traducción. Luego se desarrolló mayormente en las escuelas de L. Sauveur y M. Berlitz en los Estados Unidos.

Integrante de los llamados «métodos naturales», defendía el aprendizaje de la segunda lengua cotidiana imitando el proceso de adquisición de la materna. Para ello, partía inicialmente del uso exclusivo de la lengua meta (L2) en el aula y de la interacción oral con el profesor (generalmente, nativo) mediante preguntas, con el apoyo de gestos, objetos o dibujos. Al potenciarse el aprendizaje oral (escucha y repetición), la escritura y la gramática no se estudian hasta más adelante, y esta última de forma inductiva. La repetición imitativa, tanto de la pronunciación como de la gramática, con ejercicios de sustitución, serían sus elementos claves. El léxico se aprende de forma asociativa y en estructuras de uso cotidiano (cf. Santamaría Pérez, 2006 y S'anchez Pérez, 2009).

\subsection{El método estructural}

Aunque su origen es muy anterior, el método estructural está presente en España desde los años setenta, tras los progresos realizados en la fonología y sintaxis. Fija su atención en la gramática, que se aprende con ejercicios a través de sus estructuras más frecuentes hasta conseguir, mediante la sustitución repetitiva, la fijación de estas. Este procedimiento implica una menor atención al léxico, que, cuando aparece, lo hace supeditado a la gramática.

Ahora bien, el formalismo de este método aportó una nueva perspectiva al estudio del léxico: las palabras se integran en estructuras contextuales, generalmente repetitivas (ejercicios de rellenar huecos, drills), que promueven el aprendizaje y atienden a su combinación y distribución tanto en sus relaciones sintagmáticas (combinatorias) como paradigmáticas (contrastivas). Paralelamente se determinan los rasgos semánticos de las unidades léxicas mediante la semántica componencial (véase más arriba como ejemplo la tabla de calle/avenida/paseo...). Asimismo, los estudios de frecuencias permiten establecer una gradación del léxico acorde con la complejidad gramatical (Santamaría Pérez, 2006: 25).

\subsection{El método comunicativo}

La aparición del generativismo marcó una nueva perspectiva en el aprendizaje de segundas lenguas. Tras la aparición del concepto de competencia gramatical en los años 50 (Chomsky, Estructuras sintácticas, 1957) y del de competencia comunicativa de Hymes en los 70, el concepto de competencia, entendido como conocimiento implícito de una lengua, se traspasó al ámbito educativo para configurar la progresión y los resultados de aprendizaje. Basados en estas nuevas teorizaciones, las metodologías se replantean los modos de aprender las lenguas y esto influye en la concepción del léxico.

Este enfoque parte de que el aprendizaje de una lengua debe comprender la adquisición de habilidades que permitan interactuar con otros hablantes, tanto oralmente como por escrito. Para ello se hacen precisas cuatro destrezas: la comprensión oral y lectora y la expresión oral y escrita. Se potencia el carácter discursivo de la lengua y el léxico se integra en él de forma natural. Esto aparta el léxico de la dependencia gramatical que se daba en el 
estructuralismo $\mathrm{y}$, frente a los ejercicios repetitivos de estructuras, los métodos comunicativos integran el léxico en sus ejercicios, no como finalidad, sino como instrumento. Ello no quiere decir que el léxico haya perdido un papel relevante, sino que debe estar integrado junto con los aspectos gramaticales, con el fin de la comunicación.

Frente a la perspectiva del aprendizaje del léxico dominante en los métodos gramaticales y estructurales, mediante listas temáticas o basadas en frecuencias, en los métodos comunicativos predomina la perspectiva del uso, por lo que es común el léxico coloquial, frente a métodos más gramaticales que apuestan por un léxico más culto, orientado hacia la escritura o la comunicación formal.

El léxico se enseña de acuerdo con las necesidades específicas de los alumnos o las objetivos que quieran potenciarse en las unidades que componen el curso (presentarse, pedir información, describir caracteres, etc.), lo que favorece la organización de las unidades léxicas en áreas temáticas y campos nocio-funcionales (Santamaría, 2006: 25-26). Se parte de simulaciones que reproducen situaciones reales, por lo que para reflejar la lengua en uso se recurre a materiales auténticos y el vocabulario siempre figura contextualizado, con una importancia similar a la gramática.

\subsection{El método por tareas}

El método por tareas, como una prolongación del método orientado hacia la comunicación, surge en el ámbito anglosajón hacia los años 90 del pasado siglo XX. Promueve el aprendizaje real de la lengua mediante unos determinados objetivos encauzados mediante tareas que simulan procesos de la realidad (abrir una cuenta corriente, realizar un informe de empresa, hacer una presentación en un sector laboral, etc.). Es a lo largo de su realización cuando surge la gramática, el vocabulario y los contenidos socioculturales, de modo inverso a como se daba en los métodos anteriores. La presentación del vocabulario suele ir insertada en tareas o en ejercicios de grupo. La realización de actividades intermedias o subtareas secuenciadas favorece la interacción con otros compañeros y promueve el uso discursivo de la lengua.

\subsection{El enfoque léxico}

El enfoque léxico es uno de los más recientes. Parte de la obra The Lexical Approach (1993) de Michael Lewis, ampliada luego en otras posteriores (Lewis, 1997, 2000). Bajo este nombre se promueve el empleo de frases estandarizadas y secuencias léxicas en bloque (denominadas chunks) que permiten la comunicación (es decir, algo similar a las frases que podríamos encontrar ya escritas en guías de conversación y de viaje). Concebidas de un modo semejante a las estructuras gramaticales empleadas en los métodos estructurales, pero no supeditado a ellas, el aprendizaje se produciría por el estudio de sus combinaciones. Este enfoque supone la primacía de la oralidad y las destrezas orales.

\subsection{Otros enfoques surgidos de la Lingüística textual}

La lingüística textual también ha aportado nuevos puntos de vista, al considerar que la competencia discursiva también refuerza la léxica. Surgidas como estrategias prácticas orientadas hacia el aprendizaje del léxico, se han dado varias propuestas, como:

- El modelo de Clark \& Nation (1980): propone que se localice la palabra y se intente averiguar su significado por el contexto inmediato $\rightarrow$ inferencia.

- Bruton \& Samuda (1981) pensaron que el mejor método era hacer pensar al alumno y que adivinara el significado antes de buscarlo en un diccionario o que fuese proporcionado por el profesor. 
- El modelo de van Parreren \& Schouten-van Parreren (1982) parte del enfoque textual o discursivo, según el cual primeramente hay que hallar las partes de un texto dado, su estructura, sus enlaces, resumir el contenido y, partiendo del tema general, suponer el significado de las palabras desconocidas a través del contexto.

- El modelo de Williams (1986) prefiere identificar primero a qué partes de la oración corresponden las palabras desconocidas, mediante un análisis sintáctico, y de las palabras con las que se relacione extraer el significado. Posteriormente habrá que comprobar si el significado propuesto tiene sentido en el contexto general (pero este método puede dar lugar a una gran imprecisión, y dependerá de la competencia léxica del alumno en su lengua materna).

\section{La perspectiva actual. La competencia léxica según el Marco Europeo}

Atender con cierto detalle a lo que señala el Marco común europeo nos puede ayudar a completar la visión teórica y metodológica de la enseñanza del léxico, al ser la vigente en nuestros días. Podemos decir que, metodológicamente, el enfoque vigente es el comunicativo, complementado por el enfoque por tareas.

El Marco común europeo de referencia para las lenguas (MCER, 2002; traducción del Common European Framework of Reference for Languages, 2001) habla de competencias comunicativas de la lengua, compuestas por competencias lingüísticas, sociolingüísticas y pragmáticas. Estas incluyen también, lógicamente, el conocimiento del léxico. Para el Marco, la competencia léxica es propiamente una subcompetencia, pues está incluida dentro la competencia lingüística, junto con la gramatical, la semántica, la fonológica, la ortográfica y la ortoépica. La competencia gramatical determina la corrección del mensaje de acuerdo con las reglas lingüísticas de forma y de significado, pero, para transmitir el mensaje adecuadamente y hacer una comunicación efectiva, es, a su vez, necesario cumplir también unas reglas de interacción y contextualización, esto es, las competencias sociolingüística y pragmática. En cuanto a la competencia léxica, esta aparece precisada de la siguiente manera:

\subsubsection{La competencia léxica}

La competencia léxica, que es el conocimiento del vocabulario de una lengua y la capacidad para utilizarlo, se compone de elementos léxicos y elementos gramaticales.

Los elementos léxicos o unidades léxicas comprenden:

a. Unidades fraseológicas o unidades pluriverbales, que se componen de varias palabras que se utilizan y se aprenden como un todo. Incluyen:

○ Fórmulas fijas, que comprenden:

- exponentes directos de funciones comunicativas como, por ejemplo, saludos: Encantado de conocerle, Buenos días, etc.;

- refranes, proverbios, etc.;

- $\quad$ arcaísmos residuales; por ejemplo: Desfacer entuertos, Válgame Dios.

○ Modismos; a menudo:

- metáforas lexicalizadas, semánticamente opacas; por ejemplo: Estiró la pata (murió). Se quedó de piedra (se quedó asombrado). Estaba en las nubes (no prestaba atención);

- intensificadores, ponderativos o epítetos. Su uso es a menudo contextual y estilísticamente restringido; por ejemplo: blanco como la nieve (= «puro»), como opuesto a blanco como la pared (= «pálido»); 
- estructuras fijas, aprendidas y utilizadas como conjuntos no analizados, en los que se insertan palabras o frases para formar oraciones con sentido; por ejemplo: «Por favor, sería tan amable de + infinitivo...?».

- Otras frases hechas como:

- $\quad$ verbos con régimen preposicional; por ejemplo: convencerse de, alinearse con, atreverse $a$;

- locuciones prepositivas; por ejemplo: delante de, por medio de.

- Régimen semántico: expresiones que se componen de palabras que habitualmente se utilizan juntas; por ejemplo: Cometer un crimen/error, ser culpable de (algo malo), disfrutar de (algo bueno).

b. Palabras: una palabra puede tener varios significados distintos (polisemia); por ejemplo: tanque, un recipiente de líquido o un vehículo armado y blindado; o banco, lugar para sentarse o entidad financiera. Estas palabras incluyen miembros de las clases abiertas de palabras: sustantivo, verbo, adjetivo, adverbio, aunque éstas pueden incluir conjuntos léxicos cerrados (por ejemplo: días de la semana, meses del año, pesos y medidas, etc.). Se pueden establecer otros conjuntos léxicos con fines gramaticales y semánticos (véase a continuación).

Los elementos gramaticales pertenecen a clases cerradas de palabras; por ejemplo:

- $\quad$ artículos (el, la, los, las...)

- $\quad$ cuantificadores (algo, poco, mucho...)

- demostrativos (este, esta, estos, estas...)

- $\quad$ pronombres personales (yo, tú, él, ella, nosotros...)

- $\quad$ pronombres relativos y adverbios interrogativos (qué, cuál, quién, dónde, cómo, cuándo)

- $\quad$ posesivos $(m i, t u, s u \ldots)$

- $\quad$ preposiciones (a, ante, bajo, cabe, con, contra...)

- $\quad$ verbos auxiliares (ser, estar, haber...)

- $\quad$ conjunciones $(y, o$, pero, aunque...)

Los usuarios del Marco de referencia pueden tener presente y, en su caso, determinar:

- Qué elementos léxicos (expresiones hechas y palabras polisémicas) tendrá que aprender a reconocer y utilizar el alumno, cómo se le capacitará para ello, o qué se le exigirá al respecto.

Cómo se eligen y se ordenan tales elementos.

Figura 5. Competencia léxica. Fuente: MCER. Instituto Cervantes, $\$ 5$

El Marco deja patente la importancia de la adecuación al grupo de estudiantes de la selección del léxico y de la ordenación de los contenidos específicos (recuadro final), pero no concreta sus contenidos. Por otro lado, solo incluye aquel léxico gramatical sistematizable que ya señalábamos al inicio del artículo (clases cerradas: «elementos gramaticales») o bien las expresiones hechas («elementos léxicos», entre los que incluye los verbos con régimen preposicional, un criterio que dista de los tratamientos lexicográficos). Para las «palabras», clases abiertas, no da pautas, salvo cuando dice que «se pueden establecer otros conjuntos léxicos con fines gramaticales y semánticos», lo cual refuerza lo que ya señalamos antes: la dificultad de enseñar el léxico tomándolo como una serie abierta. 
Marta Baralo (2005) también ha observado las inconcreciones del Marco y se preguntaba por la exclusión de «las palabras con significado referencial, las que entendemos por palabras/formas/ítem léxicos», que serían, propiamente, las que compondrían la parte léxica fundamental de una lengua; también reflexiona sobre las interrelaciones entre la subcompetencia léxica y las demás subcompetencias, así como sobre los distintos planos que afectan al léxico (fónico, morfológico, sintáctico, semántico...), ya mencionados antes.

Los niveles de dominio de la competencia léxica son igual de inconcretos y muestran la difícil evaluación de los conocimientos léxicos en los niveles: así, para el nivel A1.1, según el Marco, basta con tener «suficiente vocabulario para expresar necesidades comunicativas básicas» (pero la situación comunicativa básica depende del usuario y del contexto: por ejemplo, una estudiante Erasmus deberá saber comunicarse en un ámbito académico; un inmigrante necesitará solucionar trámites laborales y de la vida cotidiana); la distinción entre un A2 y B1, igual de inconcreta, consistiría en que el A2 «tiene suficiente vocabulario para desenvolverse en actividades habituales y en transacciones cotidianas que comprenden situaciones y temas conocidos»y el B1 «tiene suficiente vocabulario para expresarse con algún circunloquio sobre la mayoría de los temas pertinentes para su vida diaria como, por ejemplo, familia, aficiones e intereses, trabajo, viajes y hechos de actualidad».

Solo en el capítulo 6.4.7.1 del Marco, sobre el desarrollo de las competencias lingüísticas, se dan algunas sugerencias concretas con las que presentar el vocabulario a los alumnos (pero se verá que son mezclas de distintas metodologías):

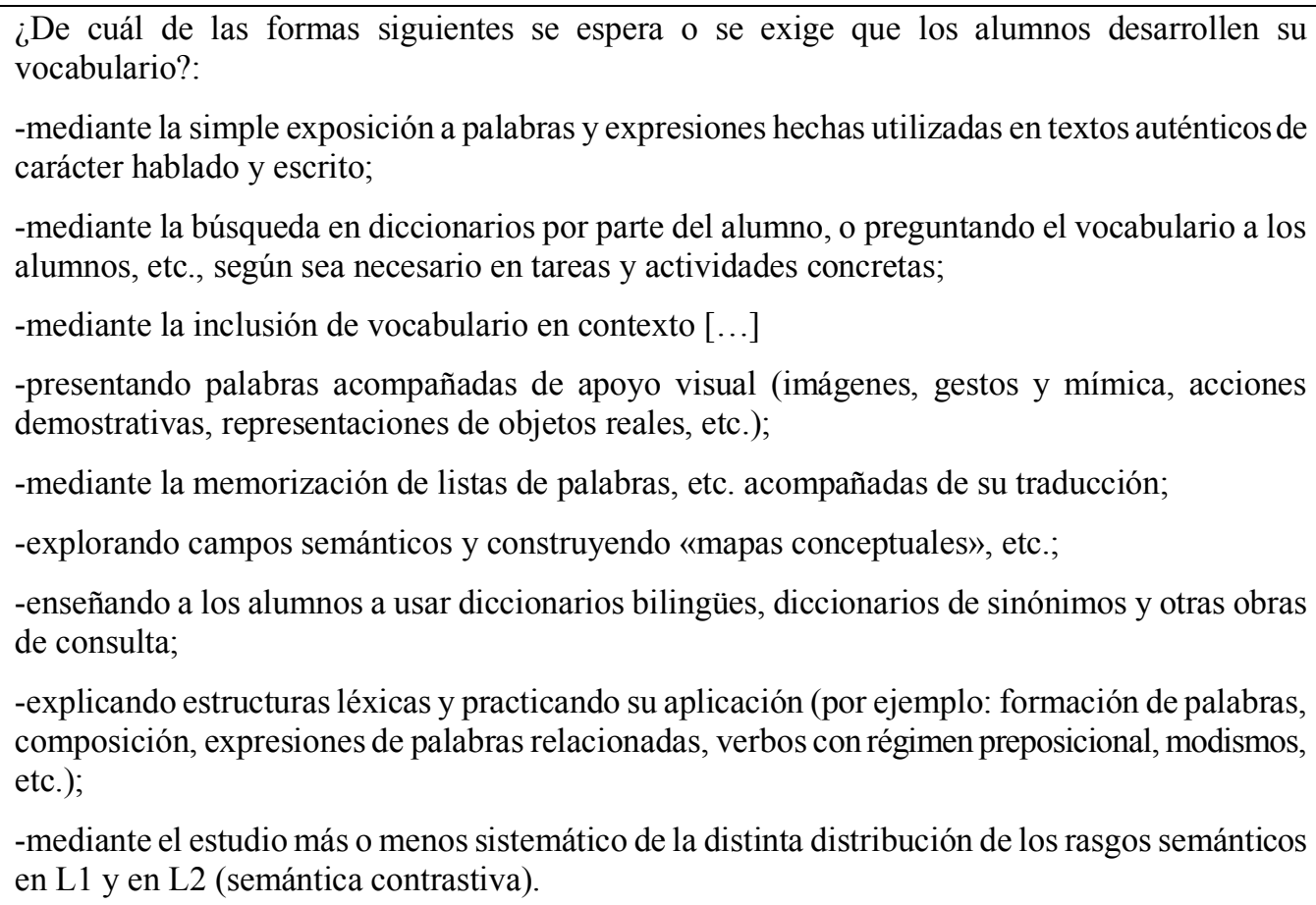

Figura 6. Sobre el desarrollo de las competencias lingüísticas.. Fuente: MCER. Instituto Cervantes, capítulo 6.4.7.1.

El apartado 6.4.7.3, sobre los criterios para la selección léxica, aboga por agrupar las voces por áreas temáticas y seguir principios léxico-estadísticos para seleccionar las más frecuentes dentro de estas, aunque pide «no realizar una planificación previa del desarrollo del vocabulario, pero permitir que se desarrolle orgánicamente en respuesta a la demanda del alumno cuando éste se encuentre realizando tareas comunicativas». 
María Teresa López-Mezquita Molina (2007: 54-55), siguiendo las propuestas de investigadores previos, defiende en cambio el uso de la planificación de actividades para la enseñanza explícita del vocabulario, pues «aceleran el proceso de aprendizaje». No obstante, no se descarta el aprendizaje indirecto o incidental, por el que el vocabulario se adquiere gradualmente, al igual que aprenden los niños las palabras de su lengua materna.

\section{Conclusiones}

A lo largo de este texto hemos visto un panorama de varias propuestas metodológicas relativas a la didáctica del léxico. Todas ellas tratan de responder a la pregunta de cómo es el aprendizaje del léxico y cómo favorecer su adquisición por parte de una persona que no conoce aún esa otra lengua. La metodología tradicional enfocaba su interés en la palabra y en la traducción a otras lenguas; la actual corriente comunicativa promueve el aprendizaje del léxico desde una perspectiva más amplia y situacional, pero indirecta, en la que el vocabulario se contextualiza oracionalmente y se usa en situaciones concretas.

Hemos partido de consideraciones teóricas, de las que han surgido posteriormente metodologías y aplicaciones prácticas; hemos descrito, finalmente, lo que señala el Marco europeo sobre la competencia léxica, con ciertas imprecisiones motivadas por la dificultad de establecer unas pautas en un sistema abierto. En todo caso, es constatable el eclecticismo que aún presentan las propuestas de enseñanza de léxico en los manuales, así como en el $M C E R$. Esto se debería, creemos, a que todas las metodologías tienen su razón de ser y se basan en alguno de los aspectos múltiples que posibilita el estudio del léxico, pues, como hemos visto, el léxico es un sistema que abarca múltiples facetas, por lo que puede ser abordado con distintas perspectivas. La combinación ecléctica de varias de esas metodologías quizá sea la opción aconsejable para los profesores. No obstante, habrá de acomodarse a las necesidades del alumno y adaptar tanto métodos como materiales a lo que exija el aula. Para ello, habrá que seguir profundizando en estas y otras futuras opciones.

\section{Bibliografía}

BARALO, M. (2005). «La competencia léxica en el Marco común europeo de referencia», Carabela, 58, 27-48. Recuperado el 12/04/2019 de: https://cvc.cervantes.es/ensenanza /biblioteca_ele/carabela/58.htm

BArfield, A. y FitzPatrick, T. (eds.) (2009). Lexical Processing in Second Language Learners: Papers and Perspectives in Honour of Paul Meara. Bristol: Multilingual Matters.

BAUER, L. (1998). Vocabulary. London, New York: Routledge.

BogAARds, P. y LAUFER, B. (eds.) (2004). Vocabulary in a Second Language: Selection, acquisition, and testing. Amsterdam/Philadelphia: John Benjamins.

CARTER, R. y MCCARTHY, M. (1988, 2016). Vocabulary and Language Teaching. New York: Longman.

CoAdy, J. y Huckin, T. (eds.) (1997). Second Language Vocabulary Acquisition. A Rationale for Pedagogy. Cambridge: Cambridge University Press.

CORPAS, L. Y MARTíneZ, J. (1999). Socios 1: Curso básico de español orientado al mundo del trabajo. Cuaderno de ejercicios. Barcelona: Difusión.

ENCINAR, Á. (1991). Palabras, palabras: Vocabulario temático. Madrid: Edelsa.

ENCINAR, Á. (2000). Uso interactivo del vocabulario. Madrid: Edelsa. 
GARCÍA GIMÉNEZ, C. (2008). La adquisición del vocabulario en la clase de ELE. Alicante: Biblioteca Virtual Miguel de Cervantes. Recuperado el 07/10/2019 de: http://www.cervantesvirtual.com/nd/ark:/59851/bmc9k4t4

GARCÍA Hoz, V. (1953). Vocabulario usual, vocabulario común y vocabulario fundamental (determinación y análisis de sus factores). Madrid: CSIC, Instituto de Pedagogía San José de Calasanz.

GARCíA Hoz, V. (1977). Estudios experimentales sobre el vocabulario. Madrid: CSIC, Instituto de Pedagogía San José de Calasanz.

GARINS, R. y REDMAN, S. (1986). Working with words. A guide to teaching and learning vocabulary. Cambridge: Cambridge University Press.

Higueras GarcíA, M. (2007). «Técnicas para la enseñanza del léxico», Mosaico. Revista para la promoción y apoyo a la enseñanza del español, 20, 37-42.

HUNSTON, S. (1997). «Grammar and vocabulary: showing the connections», ELT Journal, 51/3, 208-216.

JimÉnEz CATAlán, R. (2014): Lexical Availability in English and Spanish as a Second Language. Dordrecht: Springer.

KaufmanN, A. B. (2009). «La enseñanza del léxico». En E. de Miguel (coord.); Panorama de la lexicología (pp. 435-464). Barcelona: Ariel.

KRUSE, A. F. (1979). «Vocabulary in context», English Language Teching Journal, 33/3, 207-213.

LEWIS, M. (1993). The Lexical Approach. The State of ELT and a Way Forward. Hove: Language Teaching Publications.

LEWIS, M. (1997). Implementing the Lexical Approach. London: LTP.

LEWIS, M. (2000). Teaching Collocations: Further Developments in the Lexical Approach. London: LTP

LÓPEZ-MezQuita Molina, M. ${ }^{\mathrm{a}}$ T. (2007). La evaluación de la competencia léxica: tests de vocabulario, su fiabilidad y validez. Madrid: Ministerio de Educación y Ciencia, Subdirección General de Información y Publicaciones.

InSTITUTO CeRvantes (2002). Marco Común Europeo de Referencia (MCER). Ministerio de Educación, Cultura y Deporte. Subdirección General de Cooperación Internacional (España): Marco común europeo de referencia para las lenguas: aprendizaje, enseñanza, evaluación. Madrid: Secretaría General Técnica del MECD, Subdirección General de Información y Publicaciones. Recuperado el 10/05/2019 de: https:/cvc.cervantes.es /ensenanza/biblioteca_ele/marco/indice.htm

MEARA, P. (1983). Vocabulary in a Second Language. London: CILT.

MEARA, P. (1992). «Vocabulary in a Second Language», Reading in a Foreign Language, 9, 761-831.

MEARA, P. (2009). Connected Words : Word Associations and Scond Language Vocabulary Acquisition. Amsterdam/Philadelphia: John Benjamins.

MORAL, R. del y OLMO, L. del (2001). Manual práctico del vocabulario español. Madrid: Verbum. 
Morante VALLEJO, R.(2005). El desarrollo del conocimiento léxico en segundas lenguas. Madrid: Arco Libros.

Moreno, C. y TUTS, M. (2001). El español en el hotel. 3. ${ }^{a}$ ed. Madrid: SGEL.

Moreno Ramos, J. (2004). «Enseñar lengua desde un enfoque léxico», Glosas Didácticas, 11:162-168.

NATION, I. S. P. (1990). Teaching and Learning Vocabulary. Boston: Heinle and Heinle.

NAtion, I. S. P. (2013). Learning Vocabulary in Another Language. Cambridge: CUP.

Nunes, A. M., Vaz da Silva, A. y Duarte Mendes, H. M. (2001): «Ensino / aprendizagemn de PLE a hispanófonos. Algumas reflexões sobre o uso da preposição $a »$. Cadernos de PLE, 1, 25-41.

PABLO NúÑEZ, L. (2003). La enseñanza-aprendizaje del léxico en el español como segunda lengua: Hacia una tipología de los ejercicios léxicos a través de sus manuales. Trabajo para el curso de doctorado «La enseñanza del español como lengua extranjera» impartido en la Universidad Complutense de Madrid por el Prof. Jesús Sánchez Lobato. Inédito.

PACIOS JimÉneZ, R. M. ' (1999). Vocabulario activo e ilustrado del español: Diccionario en imágenes. 1000 palabras básicas. Madrid: SGEL.

Picoche, J. (1977). Précis de Lexicologie françaises: l'étude et l'enseignement du vocabulaire. Paris: Nathan.

RichARDS, J. y RODGERS, T. (2009). Enfoques y métodos en la enseñanza de idiomas. Madrid: Edinumen (Cambridge de didáctica de lenguas).

SAMPER Hernández, M. (2002). Disponibilidad léxica en alumnos de español como lengua extranjera. Málaga: ASELE.

SÁnchez LoBAto, J. y AguiRre, B. (1992). Léxico fundamental del español (Situaciones, temas y nociones). Glosario multilingüe. Madrid: SGEL.

SÁNCHEZ LOBATO, J. y SANTOS GARGALLO, I. (dir.) (2004). Vademécum para la formación de profesores: Enseñar español como segunda lengua (L2), lengua extranjera (LE). Madrid: SGEL.

SÁNCHEZ PÉREZ, A. (2009). La enseñanza de idiomas en los ultimos cien años: métodos y enfoques. Madrid: SGEL.

SANTAMARÍA PÉREZ, M. ${ }^{a}$ I. (2006). La enseñanza del léxico en español como lengua extranjera. Alicante: Universitat d'Alacant / Universidad de Alicante, Servicio de Publicaciones.

SANTIAGo Guervós, J. y Fernández GonZÁleZ, J. (eds.) (2017). Fundamentos para la enseñanza del español como 2/L. Madrid: Arco Libros.

Segoviano, C. (ed.) (1996). La enseñanza del léxico español como lengua extranjera: Homenaje a Anton e Inge Bemmerlein. Frankfurt am Main: Vervuert; Madrid: Iberoamericana.

SERRA AlEgre, E. y RODRÍGUEZ PELliCER, R. (2010). «Lingüística aplicada a la enseñanza del léxico». En E. Serra Alegre (coord.), La enseñanza del léxico: reflexiones teóricas y propuestas didácticas (pp. 5-10). Valencia: Universitat de València (LynX. Annexa, 19).

SOlER AlbiÑAnA, M. ${ }^{a}$ (2008). «Aspectos relacionados con la enseñanza del léxico de E/LE». En J. Martí Contreras (coord.), Teoría y práctica docente: actas del II Congreso 
Internacional de Lengua, Literatura y Cultura de E/LE (Valencia, 15-17 mayo 2008, pp. 339-350). Valencia: Universitat de València.

SUAU JiMÉNEZ, F. (2000): La inferencia léxica como estrategia cognitiva: Aplicación al discurso escrito en lengua inglesa. Valencia: Universitat de València, Dpto. Filología Inglesa y Alemana. Anejo n. ${ }^{\circ}$ XXXVII de la revista Cuadernos de Filología.

Wallace, M. J. (1982). Teaching vocabulary. London: Heinemann Educational Books (Practical Language Teaching; 10).

JIMÉNEZ GAZAPO, P. (coord.). (1991). VEN 2: Curso de español para extranjeros. Edición especial profesor. Madrid: Edelsa.

WILLIAMS, R. (1986). «Teaching vocabulary recognition strategies in ESP Reading», ESP Journal, 4, 121-131. 